\title{
Revision Bronchoscopy After Endobronchial Valve Treatment for Emphysema: Indications, Findings and Outcomes
}

\author{
Sharyn A Roodenburg $\mathbb{D}^{1,2}$ \\ Karin Klooster ${ }^{1,2}$ \\ Jorine E Hartman (iD) 1,2 \\ T David Koster (iD) ${ }^{1,2}$ \\ Marlies van Dijk (iD) ${ }^{1,2}$ \\ Dirk-Jan Slebos (iD ${ }^{1,2}$ \\ 'Department of Pulmonary Diseases, \\ University of Groningen, University \\ Medical Center Groningen, Groningen, \\ The Netherlands; ${ }^{2}$ Groningen Research \\ Institute for Asthma and COPD \\ (GRIAC), Groningen, The Netherlands
}

Correspondence: Sharyn A Roodenburg Department of Pulmonary Diseases,

AAII, University Medical Center

Groningen, Hanzeplein I, Groningen,

9713, GZ, The Netherlands

Tel +3I 503619194

$\mathrm{Fax}+310503619320$

Email s.a.roodenburg@umcg.nl
Background: Endobronchial valve (EBV) treatment is an effective treatment for patients with severe emphysema. Revision bronchoscopies after endobronchial valve treatment can be essential to prolong the effect of treatment or address long-term complications.

Purpose: To evaluate the indications, endoscopic findings and outcomes of revision bronchoscopies and investigate if any predictors for granulation tissue formation, after EBV treatment, can be identified.

Patients and Methods: Patients who underwent EBV treatment between 2016 and 2019 in our hospital, as routine care, were included. If a patient underwent a revision bronchoscopy, data regarding revision bronchoscopies, including indication, finding, intervention and pulmonary function testing (PFT) after revision bronchoscopy were analysed.

Results: One hundred seventy-nine patients were included of which $41 \%$ required at least one revision bronchoscopy. In $43 \%$ of the revision bronchoscopy patients, the indication was loss of initial treatment effect. In 53\% of the revision bronchoscopy patients, granulation tissue was found to be the underlying cause. Valve replacement(s) were performed in $51 \%$ of the revision bronchoscopy cases. Permanent valve removal was required in $13 \%$ of all patients. Overall, revision bronchoscopies led to improvements in PFT outcomes for patients experiencing no or a loss of initial treatment effect. No clinically relevant predictors for granulation tissue formation were identified.

Conclusion: Performing a revision bronchoscopy after EBV treatment is a useful procedure leading to an improved treatment effect in most patients. Granulation tissue formation, causing valve dysfunction, is the most common cause of longer term problems.

Keywords: bronchoscopy, lung volume reduction, one-way valve, COPD

\section{Introduction}

Bronchoscopic lung volume reduction using one-way endobronchial valves (EBVs) is being adopted as a treatment option for carefully selected patients suffering from severe emphysema. ${ }^{1}$ One-way valves are implanted in all airway (sub) segments of the most emphysematous lobe, after having confirmed the absence of interlobar collateral ventilation. ${ }^{2}$ The goal is to achieve a lobar atelectasis, resulting in significant volume reduction of the treated 'target' lobe which leads to a reduction of static hyperinflation..$^{3-7}$ The treatment is usually well-tolerated and results in clinically meaningful improvements in pulmonary function, exercise capacity, physical activity, and quality of life. ${ }^{3-8}$ These positive outcomes have led to the inclusion of EBV treatment in clinical guidelines making the treatment 
available for a larger number of patients worldwide. ${ }^{9,10}$ However, this increase in treatment volume will also lead to new challenges.

One of the challenges is the effectiveness and sustainability of implanted valves on the longer term. ${ }^{1}$ To prolong treatment effect or address any long-term complications, it is advised to perform an additional bronchoscopic evaluation (revision bronchoscopy) in the following situations: patients with no volume reduction approximately 6 weeks after treatment, sudden loss of treatment benefit and/or loss of volume reduction, persistent cough, persistent hemoptysis or an obstruction pneumonia. ${ }^{2,11}$ During this revision bronchoscopy, the previously placed valves are inspected and if needed cleaned, replaced or removed. ${ }^{2}$ In previous randomized controlled trials, between $19 \%$ and $39 \%$ of the patients required an additional bronchoscopic evaluation in the first year after treatment. ${ }^{1,3,4,6,7,12}$ However, minimal to no details were reported.

A possible observation during a revision bronchoscopy is the presence of granulation tissue, which has been described in the context of loss of initial treatment effect, hemoptysis and persistent cough. ${ }^{2,4,12-14}$ Granulation tissue formation is one of the therapeutic challenges of EBV treatment and for that matter in all interventional bronchoscopic procedures with lung implantable devices like stents. Although device-induced granulation tissue formation is a long-known problem, not much is known about the etiopathogenesis, or which risk factors are associated with the development of granulation tissue. For airway stents, it is suggested that bacterial colonization and mechanical irritation of the device to the airway wall are the main instigators of the inflammatory response leading to granulation tissue formation, although there is limited evidence to support this hypothesis. ${ }^{15-19}$

To date, most studies, researching EBV treatment, focused on the clinical results and short-term complications, and not on the longer-term practical challenges that come with this treatment. Since revision bronchoscopies after EBV treatment are an essential part in preserving long-term treatment effect, we set out to evaluate the indications, endoscopic findings and outcomes of revision bronchoscopies. In addition, we will address the issue of granulation tissue formation and explore whether there are patient factors before treatment that can predict the development of granulation tissue.

\section{Patients and Methods}

\section{Study Design}

This is a prospective cohort study collecting data from emphysema patients who underwent EBV treatment, as routine care, between September 2016 and September 2019 at the University Medical Centre Groningen (UMCG) and are included in the BREATHNL registry (NCT02815683). In this analysis, detailed data was collected regarding additional bronchoscopies performed after EBV treatment between September 2016 and March 2020. All patients gave written informed consent for the usage of their data for scientific purposes. This study was conducted in accordance with the Declaration of Helsinki and due to the non-invasive character of the BREATH-NL registry the ethics committee of the UMCG decided that formal ethics approval was not needed.

\section{Patient and Data Collection}

Patients treated with EBVs (Zephyr, PulmonX Corp., Redwood City, CA, USA) in our hospital were included in the analysis. Patients who underwent an additional bronchoscopy for pneumothorax management were excluded from our analysis, because this was beyond the scope of this study.

Pulmonary function testing (PFT) outcomes, total score on the Saint George Respiratory Questionnaire (SGRQ) and the 6-minute walking distance (6MWD) were collected at baseline and 6-month follow-up for all patients.

For the patients who underwent a revision bronchoscopy, the hospital admission letters, review of bronchoscopic recordings, images and reports were used to collect data on the indication for the revision bronchoscopy, main endoscopic finding and which intervention was performed during revision bronchoscopy. If a patient underwent more than one revision bronchoscopy, data were only collected for the first revision bronchoscopy. The main endoscopic finding (diagnosis of revision bronchoscopy) is defined as the most probable cause for the symptomatology of the patient.

For the patients, who underwent a revision bronchoscopy and were diagnosed with granulation tissue, we collected PFT outcomes at four time points. PFT data were collected at the following time points: (1) baseline value, (2) best value before revision bronchoscopy, (3) value before revision bronchoscopy and (4) best value after revision bronchoscopy, in case valves remained in situ. 


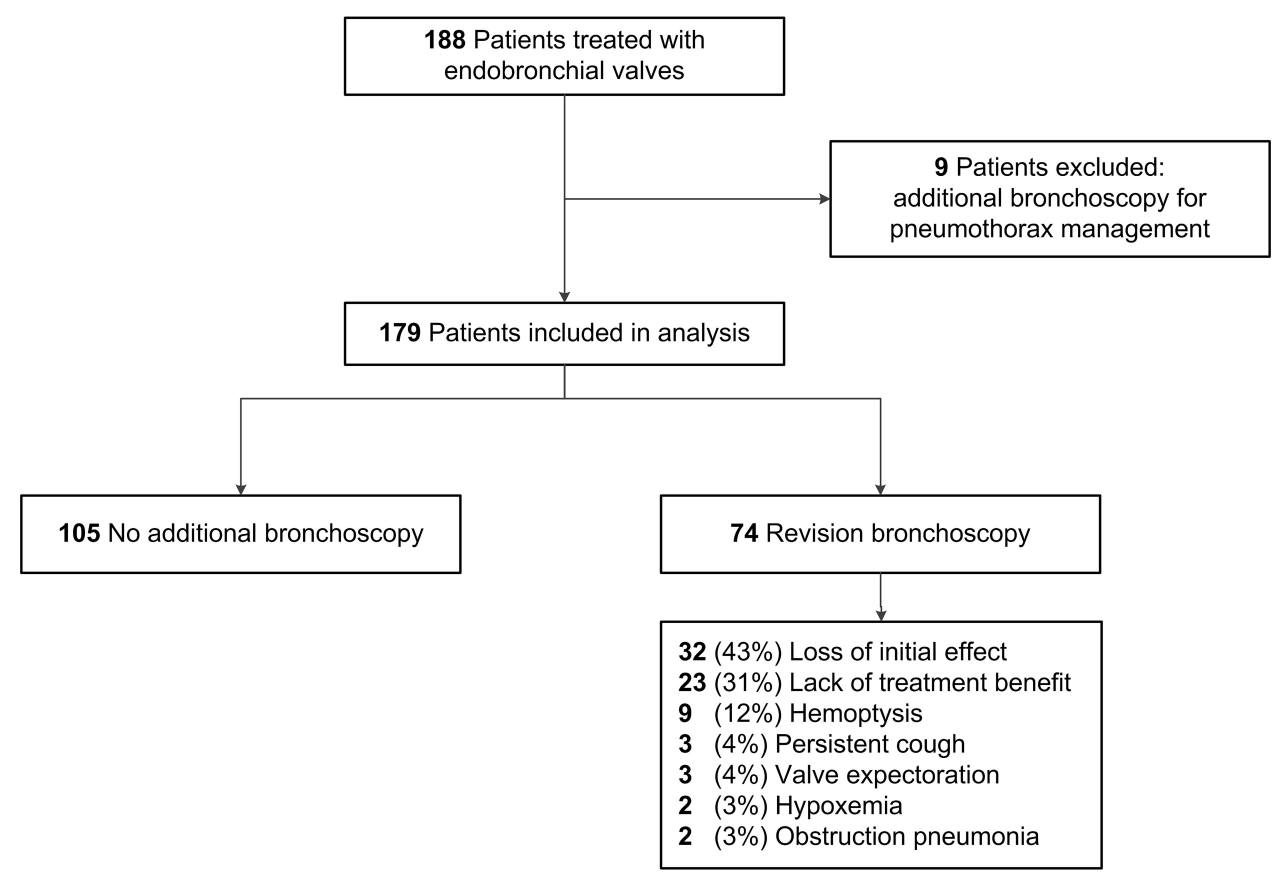

Figure I Study flow chart.

\section{Statistical Analysis}

Data are presented as mean \pm standard deviation or median (min-max). Frequency data are presented as $\mathrm{n}$ and percentage. For analysing changes in PFT outcomes, a paired sample $t$-test or a Wilcoxon signed-rank test, in case of a non-normal data distribution, was used. Patient characteristics at baseline and results of the microbiology cultures, taken prior to valve implantation, are compared between groups using an independent sample t-tests or a Fisher's exact test.

A logistic regression analysis was performed to test for any independent predictors and determine the net effect of each variable for the formation of granulation tissue after EBV treatment. Variables are entered into the analysis if univariate analysis resulted in a $p$-value $<0.2$. Backward modelling based on the log-likelihood score was used to construct the best fitting model.

All statistical analyses were performed using IBM SPSS statistics, version 23 (IBM, Armonk, USA). $P$-values $<0.05$ were considered statistically significant.

\section{Results}

In the study period, 188 patients received EBV treatment in our hospital of which 9 patients received an additional bronchoscopy for pneumothorax management and were excluded from this analysis. Therefore, 179 patients (73\% female, mean age 63 years) were included (Figure 1). The baseline characteristics are shown in Table 1. The treatment target lobe was the left lower lobe in $41 \%$ of the patients, left upper lobe in $21 \%$, right lower lobe in $18 \%$, right upper lobe in $14 \%$, right middle lobe in $3 \%$ and both the right upper and middle lobe in $3 \%$. The median follow-up time from treatment to data-analysis was 24 (6 to 42 ) months.

\section{Efficacy Outcomes of All Patients}

Six months post EBV treatment patients showed clinical meaningful improvements in pulmonary function outcomes with a mean increase in $\mathrm{FEV}_{1}$ of $184 \pm 198 \mathrm{~mL}(25 \pm 22 \%$ change from baseline), a mean decrease in RV of $677 \pm$ $685 \mathrm{~mL}$ ( $14 \pm 13 \%$ change from baseline), a decrease in total SGRQ score of $16 \pm 20$ points, and $53 \pm 70$ meter improvement on 6-minute walking test (all $p<0.01$ ).

\section{Revision Bronchoscopies}

At time of data analysis, 74 (41\%) patients underwent at least one revision bronchoscopy for an indication related to the valves. The median time from the initial treatment to the first revision bronchoscopy was 206 (21 to 1146) days (Figure 2). A second revision bronchoscopy was indicated in 24 patients and a third revision bronchoscopy in 6 patients.

\section{Indications, Findings and Interventions of Revision Bronchoscopies}

The main indications for a revision bronchoscopy were loss of initial treatment effect (32 of $74,43 \%$ ) and no or minimal 
Table I Patient Characteristics Prior to Endobronchial Valve Treatment

\begin{tabular}{|c|c|c|c|c|c|c|c|}
\hline & \multicolumn{2}{|c|}{ Total Cohort $(n=179)$} & \multicolumn{2}{|c|}{ No Granulation Tissue $(n=140)$} & \multicolumn{2}{|c|}{ Granulation Tissue $(n=39)$} & \multirow[t]{2}{*}{ p-value } \\
\hline & $\mathbf{n}$ & Value & $\mathbf{n}$ & Value & $\mathbf{n}$ & Value & \\
\hline Sex (\% female) & 179 & $73 \%$ & 140 & 71 & 39 & 77 & 0.55 \\
\hline Age (years) & 179 & $63 \pm 8$ & 140 & $63 \pm 8$ & 39 & $62 \pm 8$ & 0.51 \\
\hline BMI $\left(\mathrm{kg} / \mathrm{m}^{2}\right)$ & 179 & $24 \pm 4$ & 140 & $24 \pm 4$ & 39 & $24 \pm 4$ & 0.29 \\
\hline Smoking history (pack-years) & 178 & $43 \pm 24$ & 139 & $44 \pm 25$ & 39 & $42 \pm 20$ & 0.61 \\
\hline $\mathrm{FEV}_{\text {। }}$ (\% of predicted) & 179 & $27 \pm 10$ & 140 & $26 \pm 9$ & 39 & $28 \pm 11$ & 0.18 \\
\hline FVC (\% of predicted) & 179 & $70 \pm 25$ & 140 & $68 \pm 24$ & 39 & $74 \pm 27$ & 0.20 \\
\hline RV (\% of predicted) & 177 & $238 \pm 58$ & 138 & $237 \pm 54$ & 39 & $24 I \pm 71$ & 0.73 \\
\hline TLC (\% of predicted) & 177 & $137 \pm 14$ & 138 & $136 \pm 15$ & 39 & $140 \pm 13$ & 0.18 \\
\hline Distance on 6-minute walking test $(\mathrm{m})$ & 179 & $316 \pm 98$ & 139 & $312 \pm 99$ & 39 & $329 \pm 93$ & 0.34 \\
\hline SGRQ, total score (points) & 173 & $58.7 \pm 12.1$ & 136 & $58.9 \pm 12.3$ & 37 & $58.0 \pm 11.2$ & 0.71 \\
\hline mMRC (points) & 174 & $2.7 \pm 0.6$ & 136 & $2.8 \pm 0.7$ & 38 & $2.6 \pm 0.5$ & 0.06 \\
\hline CAT (points) & 170 & $22.3 \pm 5.2$ & 133 & $22.5 \pm 5.3$ & 37 & $21.4 \pm 4.6$ & 0.25 \\
\hline Target lobe volume $(\mathrm{mL})$ & 178 & $1846 \pm 579$ & 140 & $1787 \pm 563$ & 38 & $2064 \pm 590$ & 0.01 \\
\hline Pathogenic bacteria (\% present) & 175 & $27 \%$ & 136 & $26 \%$ & 39 & $31 \%$ & 0.64 \\
\hline Aspergillus species (\% present) & 175 & $14 \%$ & 136 & $13 \%$ & 39 & $18 \%$ & 0.44 \\
\hline Bronchitis Index Score of the target lobe ${ }^{26}$ & 104 & $5.9 \pm 2.8$ & 78 & $6.1 \pm 3.0$ & 26 & $5.2 \pm 2.1$ & 0.18 \\
\hline Bronchitis score SGRQ ${ }^{a}$ & 172 & $4.6 \pm 2.4$ & 135 & $4.6 \pm 2.4$ & 37 & $4.9 \pm 2.3$ & 0.46 \\
\hline Bronchitis score CAT ${ }^{\mathrm{b}}$ & 170 & $3.5 \pm 2.1$ & 133 & $3.6 \pm 2.1$ & 37 & $3.2 \pm 2.0$ & 0.36 \\
\hline
\end{tabular}

Notes: ${ }^{\mathrm{T}}$ Total score of part I, question I and 2 of the SGRQ. Lower scores indicate more symptoms. ${ }^{\mathrm{b}}$ Total score of question I and 2 of the CAT. Higher scores indicate more symptoms.

Abbreviations: BMI, body mass index; FEV , forced expiratory volume in I second; FVC, forced vital capacity; RV, residual volume; TLC, total lung capacity; SGRQ, St George's Respiratory Questionnaire; MMRC, modified Medical Research Council; CAT, COPD assessment test.

treatment benefit ( 23 of $74,31 \%$ ). Both indications are based on patient report combined with PFT outcomes and/or no, minimal or loss of atelectasis, of the treated lobe, on a followup CT-scan (See Figure E1 In The Supplementary Appendix). The most important parameter for categorizing a patient as having no or minimal treatment effect was the patient report in combination with not reaching the minimal important difference for target lobar volume reduction and residual volume. $^{20,21}$ The complete list of indications is shown in Figure 1. The most common diagnosis was granulation tissue formation (39 of $74,53 \%$ ) causing valve dislocation or air leakage alongside the valve as a result of weakening of the airway tissue surrounding the valve (Figures 3 and 4A). Table 2 shows the indication with the corresponding diagnosis of the revision bronchoscopy. The most frequently performed intervention during revision bronchoscopies was valve replacement
(38 of 74, 51\%) (Figure 4B and Table E1 In The Supplementary Appendix).

\section{Permanent Valve Removal}

Of the 179 patients who received valve treatment, it was necessary to permanently remove all EBVs in 24 (13\%) patients. The reasons for permanent valve removal were unsatisfactory treatment effect in 14 patients (it was suspected that 5 of these patients had collateral ventilation), severe granulation tissue formation in 5 patients, severe hemoptysis (caused by granulation tissue) in 3 patients, hypoxemia in 1 patient and obstruction pneumonia in 1 patient. In 11 patients, valves were permanently removed during the first revision bronchoscopy, in 11 patients during the second and in 2 patients during the third. 


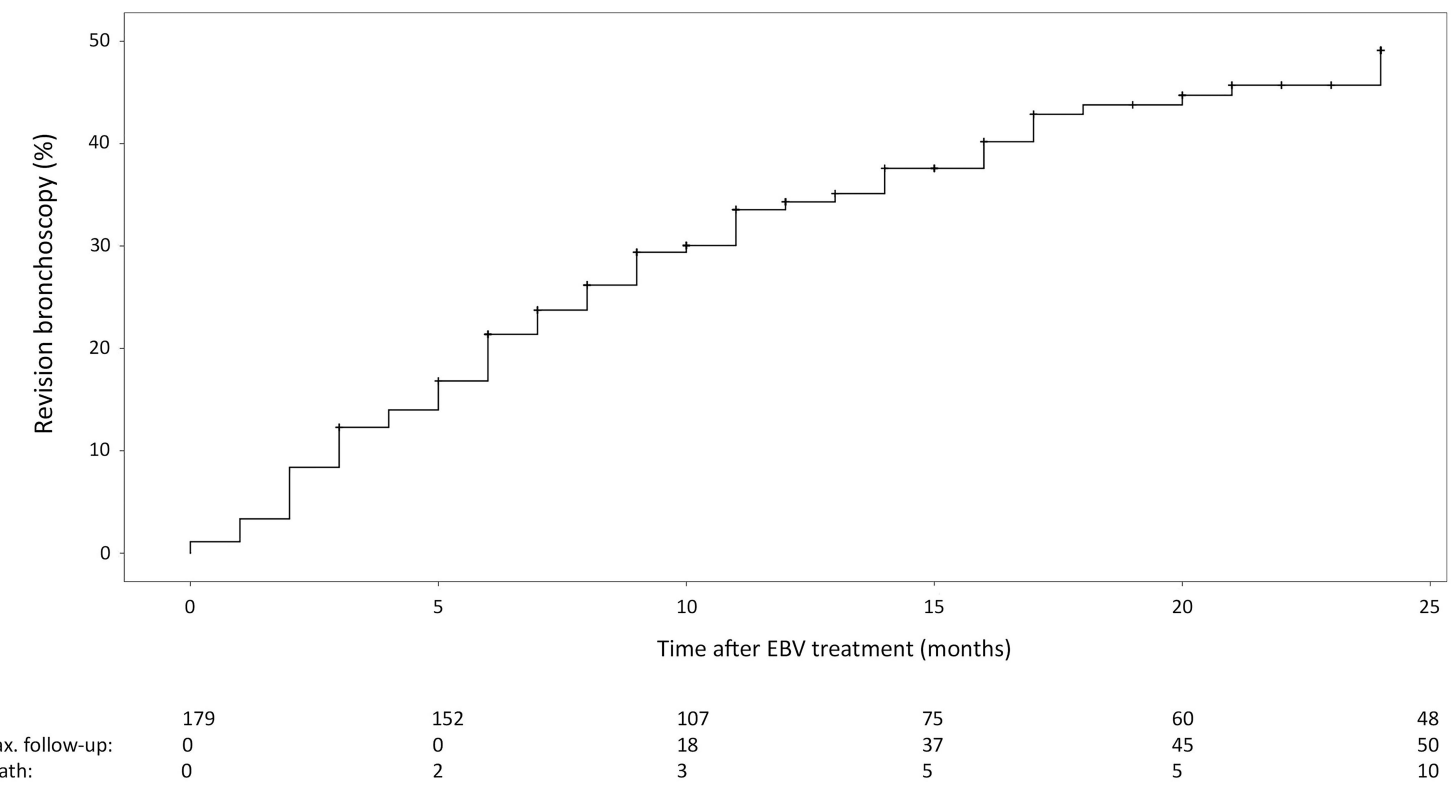

Number censored by max. follow-up: 0

18
3

Figure 2 Time to first revision bronchoscopy. Reverse Kaplan-Meier curve of cumulative percentage of patients who underwent a revision bronchoscopy against time from initial treatment for all patients $(\mathrm{N}=179)$. Patients are censored because of reaching maximum follow-up without undergoing a revision bronchoscopy or because of death without a previous revision bronchoscopy.

\section{Follow-Up Pulmonary Function Testing After Revision Bronchoscopy}

Fifty-five patients underwent a revision bronchoscopy because of no/minimal treatment effect or loss of treatment effect. In 38 of these patients $(69 \%)$, valves were retained. The PFT outcomes of these patients are shown in Table 3 . Thirty of these 38 patients performed spirometry after their last revision bronchoscopy. In $63 \%$ of the patients, the revision bronchoscopy led to an improvement in $\mathrm{FEV}_{1}$. Twenty-eight of the 38 patients performed body plethysmography after their last revision bronchoscopy. In $64 \%$ of the patients, revision bronchoscopy led to a decrease in RV.

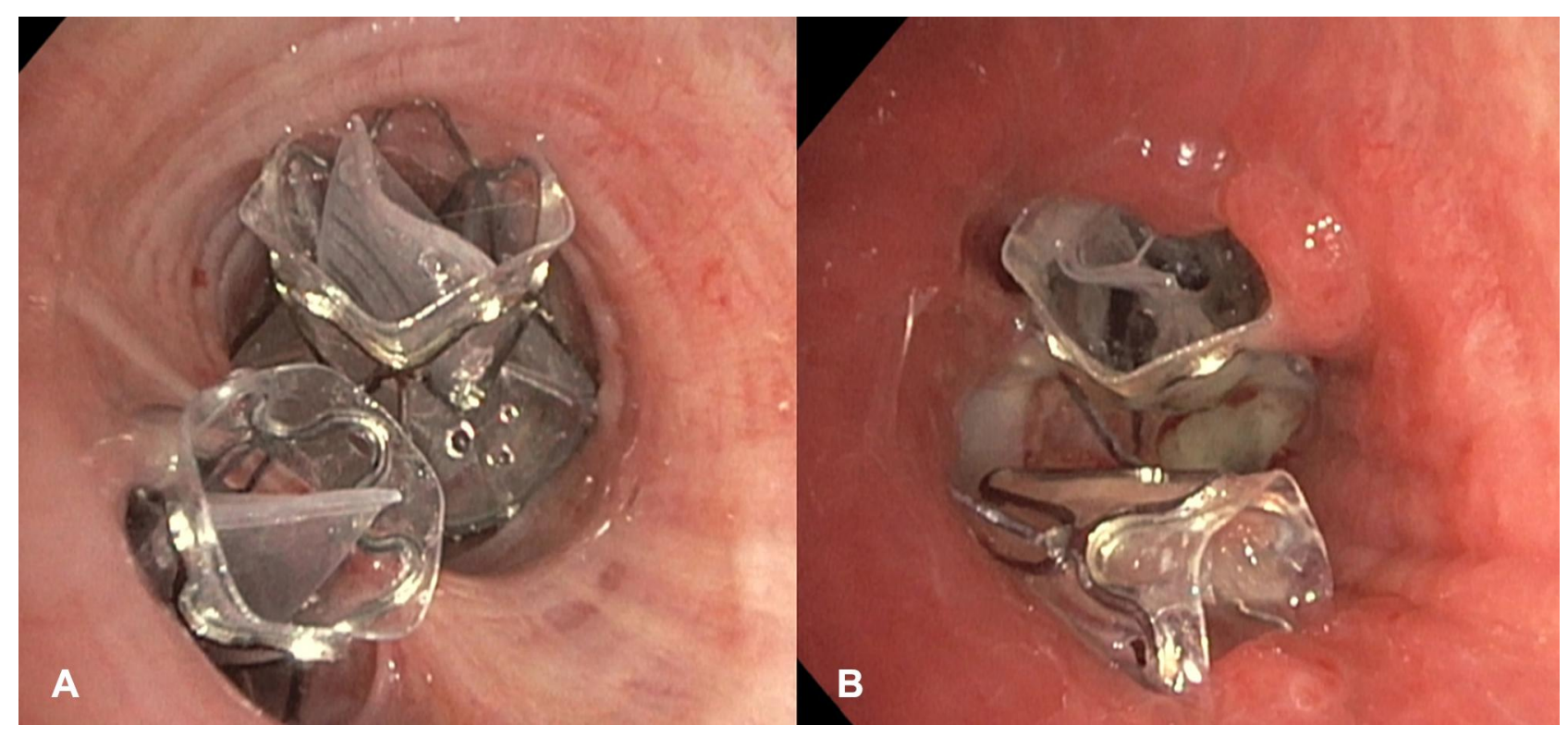

Figure 3 Endoscopic images of implanted valves in one patient. (A) Directly after implantation. (B) During revision bronchoscopy performed due to a loss of initial treatment effect. Granulation tissue has formed around the valves causing dislocation of the lower valve. 


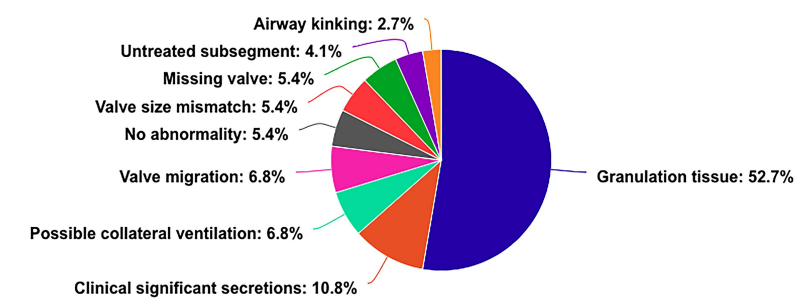

A

Figure 4 Overview of revision bronchoscopies $(n=74)$. (A) Established diagnosis during revision bronchoscopy. (B) Interventions performed during revision bronchoscopy.

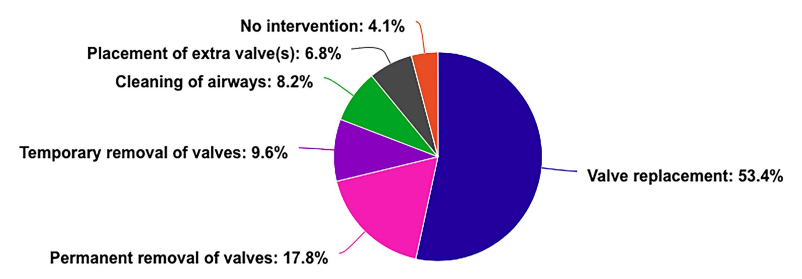

B

\section{Granulation Tissue}

Out of the 74 patients who underwent a revision bronchoscopy, 39 (53\%) patients were diagnosed with granulation tissue formation. Of these patients, 15 (39\%) required a second and $2(5 \%)$ required a third revision bronchoscopy.

The majority of the patients with granulation tissue formation (21 of 39,54\%) experienced loss of initial treatment effect (Table 2). The diagnosis of granulation tissue formation was most often followed by valve replacement (20 of $39,51 \%$ ). Furthermore, valve removal, either temporarily (5 of 39, 13\%) or permanently ( 9 of $39,23 \%$ ), was also a frequently performed intervention in the patients with valve issues related to granulation tissue formation. In case of temporarily removal, a 'cooling down' period of approximately 12 weeks was maintained before a follow-up revision bronchoscopy was performed with the intention to replace the EBVs. In three patients, severe granulation tissue persisted after the 'cooling down' period. In two of these patients, the replacement valves were implanted in a second target lobe and in one patient valves could not be replaced.

\section{Microbiology}

Prior to initial valve implantation, a $20 \mathrm{~mL}$ bronchial wash aspirate was routinely obtained in $175(98 \%)$ of all treated patients and send in for basic microbiological examination. Growth of at least one pathogenic bacterium was observed in the cultures of 48 (27\%) patients and 25 (14\%) of all cultures showed growth of aspergillus. In six of these cultures both a pathogenic bacterium as aspergillus growth was observed. H. influenzae was the most prevalent bacterium ( $\mathrm{n}=20,11 \%)$.

The cultures, obtained prior to valve implantation, showed no differences in the presence of bacteria $(p=0.64)$ or Aspergillus spp. ( $p=0.44$ ) between the 39 patients diagnosed with granulation tissue formation and all other patients (Table E2 in the supplementary appendix).
New bronchial wash aspirates were obtained, during the revision bronchoscopy, in 58 of the 74 (78\%) revision bronchoscopy patients. In $34(59 \%)$ of these cultures, at least 1 pathogenic bacterium was isolated of which 24 had no bacterial growth prior to valve implantation and 8 patients showed growth of a new bacterium. New growth of H. Influenzae (14 of 58, 24\%) and S. Aureus (10 of 58, $17 \%$ ) was most frequently observed. Overall, patients with granulation tissue showed more bacterial new growth than patients without granulation tissue ( $38 \%$ vs $68 \%, p=0.03$ ), but no difference between these groups was found for a specific pathogen (Table E3 in the supplementary appendix).

\section{Predictors of Granulation Tissue Formation}

Patients diagnosed with granulation tissue formation showed a significant higher target lobe volume, measured on CTscan, prior to treatment compared to all other patients (2064 vs $1787 \mathrm{~mL}, p=0.01$ ). All comparisons are shown in Table 1.

Based on logistic regression the "target lobe volume prior to treatment" is an independent predictor for granulation tissue formation with an odds ratio of $1.002(95 \% \mathrm{CI}$ : $1.001-1.003, p<0.01)$ when correct for gender, height and age.

\section{Discussion}

To our knowledge, this is the first study which systematically reports the indications, findings and outcomes of revision bronchoscopies after EBV treatment. We found that $41 \%$ of our patients required a revision bronchoscopy to restore and optimize EBV treatment effect or to address a longer-term complication. The median interval from the initial treatment to the first revision bronchoscopy was 206 (21 to 1145) days. Most revision bronchoscopies were performed either because of a lack of treatment benefit or because of a loss of the initial treatment effect. The 


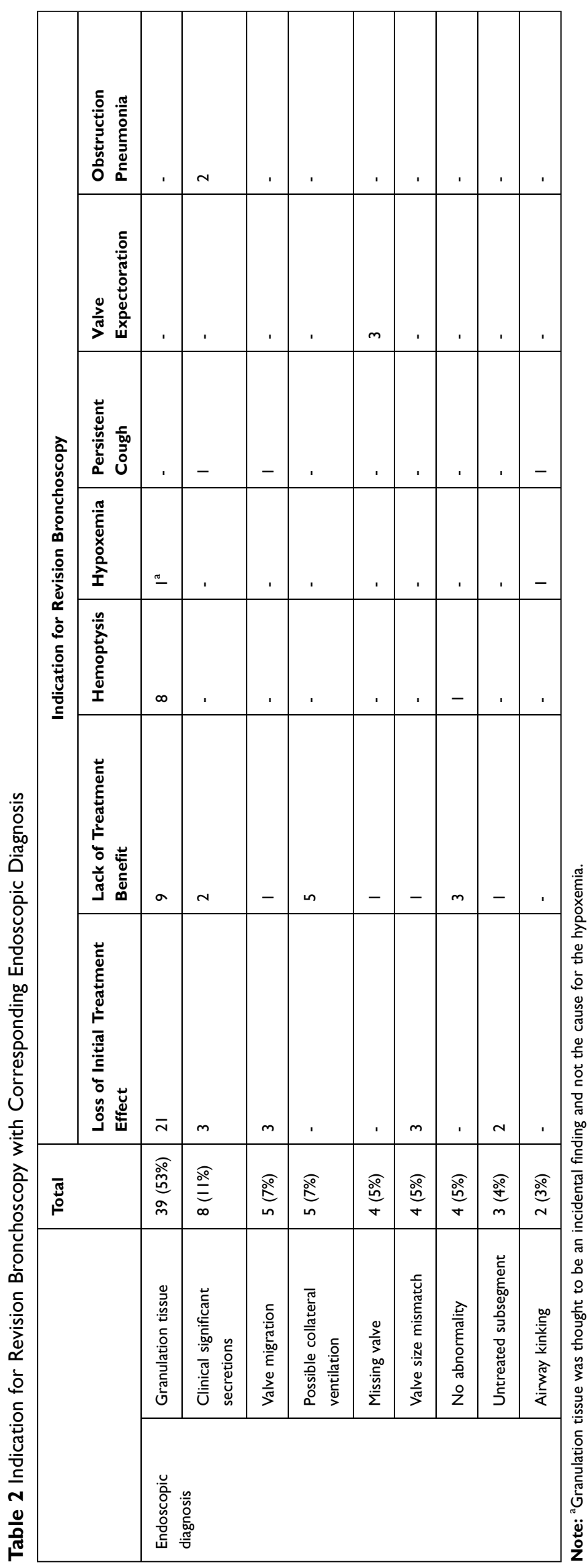




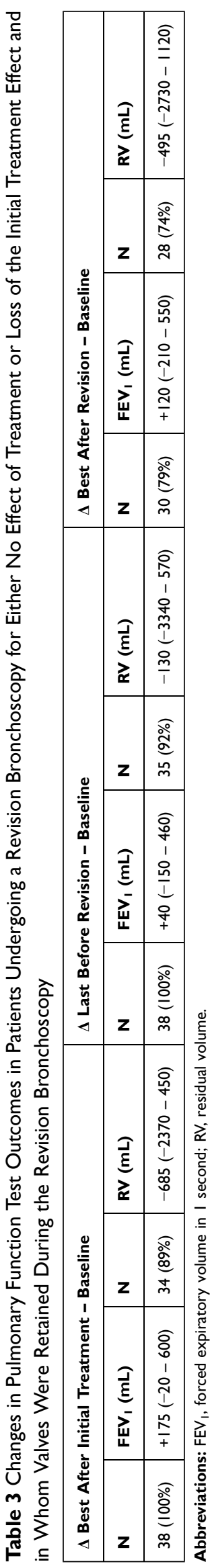

most common diagnosis during the revision bronchoscopies, found in $53 \%$ of these patients, was granulation tissue formation causing valve dysfunction or hemoptysis. The most frequent performed intervention was valve replacement. In $13 \%$ of all treated patients valves were permanently removed. This is comparable to the $17 \%$ permanent valve removal in the study of Gompelmann et al. ${ }^{13}$ The main reason for permanent removal was an unsatisfactory treatment effect for which no intervention was deemed possible or result in a satisfactory treatment effect. If EBVs were retained, the revision bronchoscopy improved the treatment effect, based on pulmonary function test outcomes, in patients experiencing no treatment effect or a loss of their initial treatment effect.

Our results showed that granulation tissue formation was the main cause of valve dysfunction after EBV treatment. It was observed in $22 \%$ of all treated patients resulting in a loss of initial treatment effect, lack of treatment benefit or hemoptysis. In most patients, the dysfunctional valve was replaced, but in $26 \%$ of the patients with granulation tissue formation valves needed to be permanently removed. In total, $46 \%$ of all permanent valve removal cases was related to granulation tissue formation. These results are in accordance with the findings in the study of Gompelmann et al who observed granulation tissue formation in $40 \%$ of the patients in whom valves were permanently removed. ${ }^{13}$ These findings highlight the importance of identifying risk factors associated with the formation of granulation tissue after EBV treatment.

We observed that a higher lobar volume of the treatment lobe is associated with an increased risk for granulation tissue formation. However, the net effect is very small considering the odds ratio approximates one. Therefore, we believe that this finding is not clinically relevant or useful in patient selection. No other predictor for granulation tissue formation was identified in our study and no previous study has focused on predictors for granulation tissue formation after EBV treatment. In contrast, granulation tissue formation after airway stenting has been studied. A number of studies suggested an association between airway colonization and the formation of granulation tissue. ${ }^{19,22}$ We found no difference in airway colonization, prior to EBV treatment, between patients diagnosed with granulation tissue formation and patients without, suggesting that bacterial presence does not affect granulation tissue formation after EBV treatment.

As for airway colonization post valve implantation, it has been previously described that the presence of valves leads to 
an increase in airway colonization. ${ }^{23} \mathrm{We}$ did indeed observe new bacterial growth after valve implantation in $55 \%$ of the patients who underwent a revision bronchoscopy. Furthermore, bacterial new growth was significantly more frequent in patients with granulation tissue formation. This could suggest an association between bacterial airway colonization after EBV treatment and the formation of granulation tissue. However, in our study, the post-valve implantation culture is obtained during the same revision bronchoscopy at which the granulation tissue formation was diagnosed. Furthermore, cultures' post-valve implantation were only available for the patients who underwent a revision bronchoscopy. Therefore, we should be careful to make a statement about causality since the direction of a potential causal relationship is unknown.

Mechanical irritation of the airway wall by an foreign body, such as valves or airway stents, has also been proposed as one of the main instigators of granulation tissue formation. ${ }^{11,15,18,24}$ Mechanical irritation can be caused by pressure of the valve on the airway wall and/or repetitive friction of the valves on the airway wall during the breathing cycle and coughing. In both cases, sizing of the EBVs will be one of the most important factors. Oversizing will cause excessive pressure on the airway wall and undersizing allows for more motion in relation to the airway causing more friction. ${ }^{15,16,25}$ Endobronchial valves are available in a limited number of sizes and can be placed at different locations in the bronchial tree. The expert opinion is that in case of valve replacement due to granulation tissue formation, the valve(s) should be replaced more distally than the initially placed valve. ${ }^{2,11}$ The movements of these smaller more distal airways during the breathing cycle are thought to be less pronounced than the movements of the more proximal airways. If the mechanical irritation due to valve movement is related to the amount of granulation tissue formation, this might be an important step in trying to prevent its formation. Valve sizing and place of insertion are not included in this study, but an analysis concerning the association between granulation tissue formation, valve size in relation to the airway size and the location of valve placement is warranted.

This study has some limitations. Firstly, the patients in our analysis have different follow-up times ranging from 6 to 42 months. However, the aim of this study is to give a general overview of the numbers, indications and outcomes of revision bronchoscopies. Secondly, we only included data of the first revision bronchoscopy. However, a substantial number of patients needed a second or even third revision bronchoscopy. In most of these patients, the indication for second (and third) revision bronchoscopy was equal or related to the indication of the first revision bronchoscopy. However, there were some patients where this was not the case, and for those patients the indication and diagnosis during the second/third revision bronchoscopy is not included in our analysis (eg, a patient underwent a first revision bronchoscopy due to valve expectoration, who later on experienced loss of treatment effect and was diagnosed with granulation tissue formation). Lastly, to evaluate the effect of a revision bronchoscopy on treatment effect, we could only include PFT data. The revision bronchoscopy patients did not undergo additional testing, such as 6-minute walking test or questionnaires, before and after their revision bronchoscopy, so this data could not be included in this analysis. Therefore, it is unknown if the improvements in PFT data led to an improvement in quality of life and/or exercise capacity.

\section{Conclusion}

Endobronchial valve treatment is a valuable and guideline recommended therapy for a selected group of patients suffering from severe emphysema. ${ }^{3-8}$ We showed that $41 \%$ all treated patients will need at least one revision bronchoscopy to optimize and restore the treatment effect or to inspect the implanted valves and adjacent airways because of a complication. In our study, the valves could be preserved in most patients, which overall resulted in improvements in the treatment effect. Our results showed that granulation tissue formation is the main longer-term complication after EBV treatment. No clinically relevant risk factor for granulation tissue formation was identified in our study. We expect that all patients, treated with EBVs, will form some degree of granulation tissue. However, not in all patients the granulation tissue causes valve dysfunction or result in another complication, such as hemoptysis. Additional research is required to unravel the underlying mechanism and risk factors for device induced granulation tissue formation in the airways. This knowledge will help to improve the longevity of the EBV treatment effect by improving patient selection, valve design/selection/placement and the treatment method in general.

\section{Funding}

There is no funding to report.

\section{Disclosure}

SR, KK, JH, TK and MD report no conflicts of interest. DS is an investigator and physician advisor to PulmonX Corp., CA, USA. 


\section{References}

1. Hartman JE, Vanfleteren LEGW, van Rikxoort EM, Klooster K, Slebos D-J. Endobronchial valves for severe emphysema. Eur Respir Rev. 2019;28(152):180121. doi:10.1183/16000617.0121-2018

2. Slebos D-J, Shah PL, Herth FJF, Valipour A. Endobronchial valves for endoscopic lung volume reduction: best practice recommendations from expert panel on endoscopic lung volume reduction. Respiration. 2017;93:138-150. doi:10.1159/000453588

3. Valipour A, Slebos D-J, Herth F, et al. Endobronchial valve therapy in patients with homogeneous emphysema results from the IMPACT Study. Am J Respir Crit Care Med. 2016;194:1073-1082. doi:10.1164/rccm.201607-1383OC

4. Klooster K, Ten Hacken NHT, Hartman JE, Kerstjens HAM, Van Rikxoort EM, Slebos DJ. Endobronchial valves for emphysema without interlobar collateral ventilation. $N$ Engl J Med. 2015;373 (24):2325-2335. doi:10.1056/NEJMoa1507807

5. Davey C, Zoumot Z, Jordan S, et al. Bronchoscopic lung volume reduction with endobronchial valves for patients with heterogeneous emphysema and intact interlobar fissures (the BeLieVeR-HIFi study): a randomised controlled trial. Lancet. 2015;386(9998):1066-1073. doi:10.1016/S0140-6736(15)60001-0

6. Criner GJ, Sue R, Wright $S$, et al. A multicenter randomized controlled trial of zephyr endobronchial valve treatment in heterogeneous emphysema (LIBERATE). Am $J$ Respir Crit Care Med. 2018;198:1151-1164. doi:10.1164/rccm.201803-0590OC

7. Kemp SV, Slebos D-J, Kirk A, et al. A multicenter randomized controlled trial of zephyr endobronchial valve treatment in heterogeneous emphysema (TRANSFORM). Am J Respir Crit Care Med. 2017;196:1535-1543. doi:10.1164/rccm.201707-1327OC

8. Hartman JE, Klooster K, Slebos D-J, Ten Hacken NHT. Improvement of physical activity after endobronchial valve treatment in emphysema patients. Respir Med. 2016;117:116-121. doi:10.1016/j. rmed.2016.06.009

9. Global Initiative for Chronic Obstructive Lung Disease. Global strategy for the diagnosis, management, and prevention of chronic obstructive pulmonary disease; 2020. Available from: www.gold copd.org. Accessed July 7, 2020.

10. National Institute for Health and Care Excellence. Endobronchial valve insertion to reduce lung volume in emphysema; 2017. Available from: https://www.nice.org.uk/guidance/ipg600. Accessed July 7, 2020.

11. Koster TD, Klooster K, Ten Hacken NH, van Dijk M, Slebos D-J. Endobronchial valve therapy for severe emphysema: an overview of valve-related complications and its management. Expert Rev Respir Med. 2020;14:1235-1247. doi:10.1080/17476348.2020.1813571

12. Klooster K, Hartman JE, Ten NHT, Dirk H, Slebos J. One-year follow-up after endobronchial valve treatment in patients with emphysema without collateral ventilation treated in the STELVIO Trial. Respiration. 2017;93:112-121. doi:10.1159/000453529

13. Gompelmann D, Gerovasili V, Kontogianni K, et al. Endoscopic valve removal $>180$ days since implantation in patients with severe emphysema. Respiration. 2018;96(4):348-354. doi:10.1159/000489887
14. Herth FJF, Noppen M, Valipour A, et al. Efficacy predictors of lung volume reduction with Zephyr valves in a European cohort. Eur Respir J. 2012;39(6):1334-1342. doi:10.1183/09031936.00161611

15. McGrath DJ, Thiebes AL, Cornelissen CG, et al. Evaluating the interaction of a tracheobronchial stent in an ovine in-vivo model. Biomech Model Mechanobiol. 2018;17(2):499-516. doi:10.1007/ s10237-017-0974-7

16. Hu H-C, Liu Y-H, Wu Y-C, et al. Granulation tissue formation following Dumon airway stenting: the influence of stent diameter. Thorac Cardiovasc Surg. 2011;59(03):163-168. doi:10.1055/s-00301250667

17. Chung F-T, Lin S-M, Chou C-L, et al. Factors leading to obstructive granulation tissue formation after ultraflex stenting in benign tracheal narrowing. Thorac Cardiovasc Surg. 2010;58(02):102-107. doi:10.1055/s-0029-1186266

18. Ost DE, Shah AM, Lei X, et al. Respiratory infections increase the risk of granulation tissue formation following airway stenting in patients with malignant airway obstruction. Chest. 2012;141 (6):1473-1481. doi:10.1378/chest.11-2005

19. Reza Nouraei SA, Petrou MA, Randhawa PS, Singh A, Howard DJ, Sandhu GS. Bacterial colonization of airway stents: a promoter of granulation tissue formation following laryngotracheal reconstruction. Arch Otolaryngol - Head Neck Surg. 2006;132 (10):1086-1090. doi:10.1001/archotol.132.10.1086

20. Welling JBA, Hartman JE, van Rikxoort EM, et al. Minimal important difference of target lobar volume reduction after endobronchial valve treatment for emphysema. Respirology. 2018;23(3):306-310. doi: $10.1111 /$ resp. 13178

21. Hartman JE, Ten Hacken NHT, Klooster K, Boezen HM, De Greef MHG, Slebos DJ. The minimal important difference for residual volume in patients with severe emphysema. Eur Respir J. 2012;40(5):1137-1141. doi:10.1183/09031936.00219111

22. Schmäl F, Fegeler W, Terpe HJ, Hermann W, Stoll W, Becker K. Bacteria and granulation tissue associated with Montgomery T-tubes. Laryngoscope . 2003;113(8):1394-1400. doi:10.1097/00005537200308000-00024

23. Sarmand N, Gompelmann D, Kontogianni K, Polke M, Herth FJ, Eberhardt R. New bacterial growth in bronchial secretions after bronchoscopic valve implantation. Int $J$ Chron Obstruct Pulmon Dis. 2018;13:565-570. doi:10.2147/COPD.S148196

24. Debiane L, Reitzel R, Rosenblatt J, et al. A design-based stereologic method to quantify the tissue changes associated with a novel drug-eluting tracheobronchial stent. Respiration. 2019;98(1):60-69. doi: $10.1159 / 000496152$

25. Saad CP, Murthy S, Krizmanich G, Mehta AC. Self-expandable metallic airway stents and flexible bronchoscopy: long-term outcomes analysis. Chest. 2003;124(5):1993-1999. doi:10.1378/ chest.124.5.1993

26. Thompson AB, Huerta G, Robbins RA, et al. The bronchitis index. Chest. 1993;103(5):1482-1488. doi:10.1378/chest.103.5.1482

\section{Publish your work in this journal}

The International Journal of COPD is an international, peer-reviewed journal of therapeutics and pharmacology focusing on concise rapid reporting of clinical studies and reviews in COPD. Special focus is given to the pathophysiological processes underlying the disease, intervention programs, patient focused education, and self management protocols. This journal is indexed on PubMed Central, MedLine and CAS. The manuscript management system is completely online and includes a very quick and fair peer-review system, which is all easy to use. Visit http://www.dovepress.com/testimonials.php to read real quotes from published authors. 